\title{
Exploring consumer behavior and policy options in organic food adoption: Insights from the Australian wine sector
}

\author{
Firouzeh Taghikhah $^{\mathrm{a}, *}$, Alexey Voinov ${ }^{\mathrm{a}, \mathrm{b}}$, Nagesh Shukla ${ }^{\mathrm{a}}$, Tatiana Filatova ${ }^{\mathrm{b}, \mathrm{a}}$ \\ ${ }^{a}$ Center on Persuasive Systems for Wise Adaptive Living, School of Information, Systems and Modelling, Faculty of Engineering and Information Technology, University of \\ Technology Sydney, NSW 2007, Australia \\ ${ }^{\mathrm{b}}$ University of Twente, Netherlands
}

\section{A R T I C L E I N F O}

\section{Keywords:}

Sustainable food

Organic agriculture

Social interactions

Behavioral theory

Consumption pattern

Complex systems

\begin{abstract}
A B S T R A C T
Organic food has important environmental and health benefits, decreasing the toxicity of agricultural production, improving soil quality, and overall resilience of farming. Increasing consumers' demand for organic food reinforces the rate of organic farming adoption and the level of farmers' risk acceptance. Despite the recorded $20 \%$ growth in organically managed farmland, its global land area is still far less than expected, only $1.4 \%$. Increasing demand for organic food is an important pathway towards sustainable food systems. We explore this consumer-centric approach by developing a theoretically- and empirically-grounded agent-based model. Three behavioral theories - theory of planned behavior, alphabet theory, and goal-framing - describe individual food purchasing decisions in response to policies. We take wine sector as an example to calibrate and validate the model for the case study of Sydney, Australia. The discrepancy between consumer intention and purchasing behavior for organic wine can be explained by a locked-in vicious cycle. We assess the effectiveness of different policies such as wine taxation, and informational-education campaigns to influence consumer choices. The model shows that these interventions are non-additive: raising consumer awareness and increasing tax on less environmentally friendly wines simultaneously is more successful in promoting organic wine than the sum of the two policies introduced separately. The phenomenon of undercover altruism amplifies the preference for organic wine, and the tipping point occurs at around 35\% diffusion rate in the population. This research suggests policy implications to help decision-makers in the food sector make informed decisions about organic markets.
\end{abstract}

\section{Introduction}

Food production-consumption is one of the most energy and resource-intensive activities of modern civilization. It accounts for $15-20 \%$ of the total global anthropogenic greenhouse gas (GHG) emissions (Woods et al., 2010) and has a significant environmental impact. Expanding conversion of natural habitat to agricultural land is the main driver of global forest loss and species extinction. Since the introduction of chemical fertilizers in the 19th century, food production has significantly contributed to a wide range of environmental problems. Organic agriculture, as part of the solution, can largely reduce the overall environmental footprint of food production by eliminating the application of chemical fertilizers and pesticides and reducing energy use (Pizzigallo et al., 2008). According to the 2019 IPCC report (IPCC, 2019), by changing diets, and in particular, by transitioning to organic food production and consumption we can reverse environmental losses and avoid ecosystem collapse. There are examples of quite successful and productive organic farmlands, where species diversity and soil quality are substantially higher than in conventional systems (Wilbois \& Schmidt, 2019). Organic food also contains higher levels of nutrients, improves consumers' health and wellness. Organic diets have been convincingly exposing consumers to fewer chemicals associated with human diseases such as cancer, autism, and infertility (Hyland et al., 2019).

While organic farming is more sustainable, it usually produces lower crop yields in comparison to conventional agriculture, resulting in higher food prices. Consumer food preferences and higher interest in organic food can be a turning point in motivating farmers to adopt organic farming practices (Wheeler, 2008). Therefore, by purchasing organic food, people not only improve their health and well-being but also subsidize eco-friendly agriculture.

In 2018, the global sales of organic food reached US\$ 89.7 billion, a

\footnotetext{
* Corresponding author.

E-mail addresses: Firouzeh.Taghikhah@uts.edu.au, Firouzeh.th@gmail.com (F. Taghikhah), Alexey.Voinov@uts.edu.au (A. Voinov), Nagesh.Shukla@uts.edu.au (N. Shukla), Tatiana.Filatova@uts.edu.au (T. Filatova).
} 
$10 \%$ increase from the previous year. The United States has the biggest organic market by value (Mosier \& Thilmany, 2016). Germany, France, Italy, and Spain also started their organic consumption-production movement turning Europe into the second-largest organic food market. Still, the average share of organic food spending remains low (Lawson et al., 2018). Despite the efforts in promoting organic farming, according to the International Federation of Agriculture Movements, only $1.4 \%$ of global farmland was organic in 2019.

There are a number of reasons for the lower interest in organic food. According to a recent Australian organic market report (2018), higher prices, lack of trust, and lack of knowledge are identified as the top three barriers for organic purchases. In general, Australians do not value organic products much more than conventional ones, are not willing to pay more for sustainability features, and are much less willing to pay premium prices for organic food (Lockshin \& Corsi, 2012). As a result, farmers lack the motivation to continue their organic farming.

A specific sector of the food market consists of so-called vice products. Vices and virtues are typically defined relative to one another. Vice foods or "wants" refer to products that are more gratifying and appealing in the short term but have negative health impacts in the long-term such as chocolate, chips, wine. On the contrary, virtue food or "shoulds" may not possess the hedonic allure of vices or immediate pleasurable experience but provide utilitarian benefits. Generally, consumers are highly motivated to consume more vice food rather than virtue food. Research indicates that organic labels of vice and virtue food types may cause different responses among consumers (MartinezCarrasco et al., 2005). On the one hand, Van Doorn and Verhoef (2011) report that consumers pay more price premiums for organic virtue food in comparison to vices due to negative quality connotations for vice products.

On the other hand, Lee et al. (2018) show mixed results, where the organic label on vice food both increases and decreases food intake depending on consumer characteristics. They declare that consumers' perception of external and internal health control is the mediating factor in decisions between organic and conventional alternatives. A consumer who believes in external control is more likely to buy organic vice food because that provokes a guilt-reduction mechanism. A consumer being driven by internal health control may choose to do the opposite. The choice of organic in vice and virtue products is still an ongoing topic calling researchers for further studies (Hidalgo-Baz et al., 2017).

Empirical research on organic food preferences, so far, could not provide a clear understanding of the extent of interventions that can influence the behavior of consumers (Tait et al., 2019). In many cases, running an experiment requires much time (Bernabéu et al., 2013), and efforts before reaching the desired results, if reaching them at all. These limitations emphasize the need for methods that complement the empirical information about the complex behavior of organic consumers. System models can improve our understanding of the complexity of food purchasing decisions. Models are useful for designing interventions, comparing policy options, testing theories, and scaling behavioral patterns observed in experimental and field data. While statistical approaches are strong in revealing patterns in data, modeling methods such as agent-based modeling (ABM) add value by exploring causal connections behind system-level phenomena and patterns. ABMs not only study macro-level patterns emerging from actions of heterogeneous agents and their interactions with each other but also show the downward causation where the behavior of individuals at the microlevel is influenced by collective actions (Jager and Ernst, 2017). This makes ABM a suitable method for studying the complexity of cumulative market effects of individual behavior changes, especially for food preferences, where emerging social norms add uncertainty about future consumption choices.

ABMs becomes a key research method to explore the dynamics and impact of behavioral changes in marketing, food, health, and environmental sciences. Hu et al. (2018) examine the impact of promotional and marketing activities on consumer preferences. Li et al. (2018) develop a model for assessing the impact of access and price on New York's fruit and vegetable consumption. Garcia et al. (2007) address validation issues for $\mathrm{ABM}$ in the field of marketing, focusing on the wine industry. Recent environmental applications include studying behavior change in energy markets (Niamir et al., 2018), low-emission cars (Kangur et al., 2017), waste management (Rangoni \& Jager, 2017) and climate change adaption (Erdlenbruch \& Bonté, 2018). Yet, the evidence on the impact of behavior change interventions on consumer preferences for organic food is scarce.

We address this gap by developing a computational model to simulate the decision-making process and explore the key stimuli that lead people to make choices between organic and non-organic wines in the complex shopping environment. A spatial ABM - ORganic Vine (ORVin) - explores the cumulative market consequences of individual consumer choices affected by behavioral biases and social influence. To gain insights into the process of organic wine consumption, we consider the Theory of Planned Behavior (TPB) (Ajzen, 1985) along with the Alphabet Theory (Zepeda \& Deal, 2009) and the Goal Framing Theory (Lindenbrg \& Steg, 2013). ${ }^{1}$ We apply the model to the case of the Sydney Metropolitan Area by incorporating the results of a published survey about the wine preferences of 2099 heterogeneous households. The innovative contribution of this paper is three-fold. Firstly, we develop an $\mathrm{ABM}$ to advance knowledge about the effectiveness of behavior change policy instruments on diets by explicitly considering consumer perceptions of and preferences for organic products. Within the scarce modeling literature on behavioral change towards sustainable food, this is the first simulation model proposed to understand bottomup choices between organic and non-organic wine and the policies that can impact them. Secondly, we explicitly trace the effects of social interactions, drinking habits, and desirability factors on wine consumption behavior. Regardless of its taste, wine is greatly associated with festivity, fraternity, social norm, and rarely consumed alone. Previously, social norms have not been considered as a factor for wine consumption behavior, yet they strongly influence how consumers choose organic products. Thirdly, this model can help to understand how to persuade consumers to make healthier choices when dealing with vice products such as wine. Since organic wine is hardly perceived to be of higher quality than conventional wine, it is considered as an exception to the subjective norm. Appendix A in supplementary data provides a detailed introduction with more references.

\section{Methods}

\subsection{Case study}

There is growing public concern about the environmental consequences of wine production. These issues are mainly related to water scarcity (Castex et al., 2015), land-use change, and greenhouse gas emissions (Fleming et al., 2015). Yet, while $42 \%$ of Germans reported willingness to purchase organic wines, the organic wine market in Germany is relatively small, around 3.5\% (Schäufele and Hamm, 2018). In Australia, the 5th leading country in wine production, organic wine occupies only $6.9 \%$ of the total organic market, although a $120 \%$ rise was reported in the organic grape production from 2011 to 2014 (O'Mahony and Lobo, 2017). In comparison to the wide consumption of organic milk and dairy products $(22.3 \%)$, meats (16.2\%), fruits and vegetables (11.9\%) together comprising $50 \%$ of the Australian organic market, organic wine consumption did not grow significantly (Mascitelli et al., 2014). Although the wine industry has already

\footnotetext{
${ }^{1}$ Appendix B in supplementary data extensively explains how we conceptually connect these theories to understand the decision-making process in the wine context.
} 
engaged in climate change adaption, the adaptive purchasing behavior of wine consumers is yet to be investigated.

Organic wines have a higher content of antioxidants (30\% more) and taste better than conventional wines. They often contain less preservatives, such as sulphur dioxide that is used for inhibiting unwanted yeasts and bacteria and is the main cause of headaches and hangovers (Amato et al., 2017). Unfortunately, public awareness about health and environmental benefits of organic wines is rather limited as many people assume that all wines are produced in natural, organic ways.

Prior studies have reported that most grocery and supermarket shopping behaviors are unplanned (Forbes, 2014). Hence, consumers have the temptation to purchase products without planning in advance. However, research on wine purchase behavior in a number of developed countries confirms that wine is an exceptional product. Particularly, in Australia, a relatively high level of planned purchasing behavior is reported. When purchasing wine, consumers look for attributes such as the country and region of origin, grape variety, price, and brand (Panzone, 2014). In addition to these traditional wine attributes, sustainability labels and cues add to the complexity of consumer choices. While the bulk of literature on wine consumers focuses on studying purchase behaviors, there is not much research on drivers related to sustainability.

A review of literature on organic wine markets shows that a set of factors are involved in the choice of organic wines (Di Vita et al., 2014). Among these factors, we find socio-demographics (D'amico et al., 2014), information seeking, knowledge, and beliefs (Loose and Lockshin, 2013), wine characteristics (Panzone, 2014), habit (Pomarici and Vecchio, 2014), and social and personal norms. Regarding consumer characteristics, millennials, females, and frequent wine consumers are more likely to choose organic wine. Moreover, consumers' environmental consciousness and health beliefs, which predict their attitudes, are also positively correlated with organic wine purchasing behavior. Specific extrinsic attributes of the product, such as lower prices, higher quality, and organic labels, can all determine a greater consumer willingness for purchasing organic wines. Consumers who more frequently purchase wine reported higher interest in wines with sustainability attributes (D'amico et al., 2014); however, being stuck in a conventional wine shopping routine (habits) can lead to reverse outcomes. Although social desirability is an important issue for purchasing wine, especially organic, its influence on the wine purchase decision is yet to be addressed. As wine is largely a social product, subjective influence can have a direct impact on the acceptance or rejection of organic wine (Barber, 2012). Recently, Boncinelli et al. (2019) found that consumer wine choices are occasion-specific. They confirmed that people give greater value to organic certification attributes when purchasing red wine for gift-giving occasions. In another study, Galati et al. (2019) identify convivial drinking occasions as the explanatory variable with the highest impact on willingness to pay more for organic wine. A comprehensive review of these factors can be found in Schäufele and Hamm (2017).

\subsection{Computational agent-based model of consumer behavior}

Based on theoretical and empirical micro-foundations, we develop the ORVin ABM to understand consumer purchasing behavior regarding organic wines. Here, we briefly explain the model structure and properties and provide detailed documentation in Appendix C in supplementary data.

The ORVin model simulates the behavior and interactions between two agent classes: households and wine retailers. In particular, it explores household preferences for organic wine for a sample of households in Sydney, Australia. The city of Sydney is approximately 26.15 square kilometers and is home to over 103,844 estimated households with an average size of 2.2 in 2016 . The wine retailer agents base their decisions regarding the wine stock in a rational manner to meet the local demand. Retailer agents differ in location but sell the same types of wine bundles. Organic and conventional wine prices are based on data provided by the Australian Government via 'Wine Australia ${ }^{2}$ ': at least AU\$10.00 and 13.00 per bottle, respectively (taxes included).

A consumer agent - one household member purchasing weekly groceries of the family - is modeled in a cognitively rich manner. Hence, consumer agents are heterogeneous not only in socio-economic attributes, geographic coordinates of residence, and wine shopping routines but also in their ability to learn, habits, perceived behavior control (PBC), and social norms. To gain insights into the process of organic wine consumption, we consider the Theory of Planned Behavior (TPB) (Ajzen, 1985) along with the Alphabet Theory (Zepeda \& Deal, 2009) and the Goal Framing Theory (Lindenbrg \& Steg, 2013). TPB is the most utilized theoretical framework to study organic food purchasing intention (Guido et al., 2010). The other two theories examine the role of psychological (e.g., habitual purchasing) and functional (e.g., contextual-environmental cues) factors on organic food consumption. This provides a solid theoretical framework for identifying cognitive and product-related factors (beliefs, attitudes, norms, habits, and goals) that may influence organic wine purchases. While prior literature attempted to explore the consumer intention for organic food, the barriers between organic food purchasing intention and behavior have been far less studied (Kushwah et al., 2019).

For consumer agent parametrization, we use the results of Ogbeide (2013), who used a sample of 2099 responses (representative of the Australian population) to understand the factors affecting the willingness to pay for organic wine. Due to uncertainty in data, the initial conditions of several parameters such as the number of bottles per purchase, maximum expenditure on a bottle of wine, leaning capacity, etc. are determined as stochastic values (See Appendix C.2 in supplementary data).

Looking into the existing literature on organic wine purchasing, we could not find any study reporting data on social network characteristics. Nevertheless, when it comes to alcohol drinking behavior, social disorganization theory (Sampson, 1993) highlights the importance of neighborhood environments (Shih et al., 2017). So, the social network of each household (macro-level network) includes neighbors living up to $400-800 \mathrm{~m}$ away from them. The defined neighborhood type and buffer may influence the estimation of neighborhood effects (i.e., the effect of a particular neighborhood characteristic on wine choice) (Duncan et al., 2013). Individual relationships with peers and friends may modify neighborhood effects but are not included here due to the lack of data. Hence, ORVin focuses only on social interactions with neighbors where households exchange information about wine preferences and continuously update their perceived subjective norms about wine types. We also define another immediate social environment for each household: their observations of the wine choices of the surrounding consumers in shops (meso-level network). This social influence assumption is in line with the study of Scalco (2017) on consumer behavior for organic food. The number of social contacts that households may have is not predefined and is generated during the model run.

For this model, we define two sets of user-defined control variables: (1) tax rate (affecting wine prices) and (2) level of informational marketing activities (i.e., awareness and knowledge about organic wine). The production rate of organic and conventional wines and the delivery time of products are static. ORVin is programed in AnyLogic Software, and the code is available online ${ }^{3}$. Most of households report shopping for wine at least once per week, and thus, the time step in the model is set to one week and run it for 600 weeks. Fig. 1 schematically shows the weekly wine shopping journey of a consumer.

Following TPB, households make planned purchase decisions

\footnotetext{
${ }^{2}$ http://www.wineaustralia.com/

${ }^{3}$ https://www.comses.net/codebase-release/ef1972de-dff7-4d86-95e26509fa4443ba/
} 


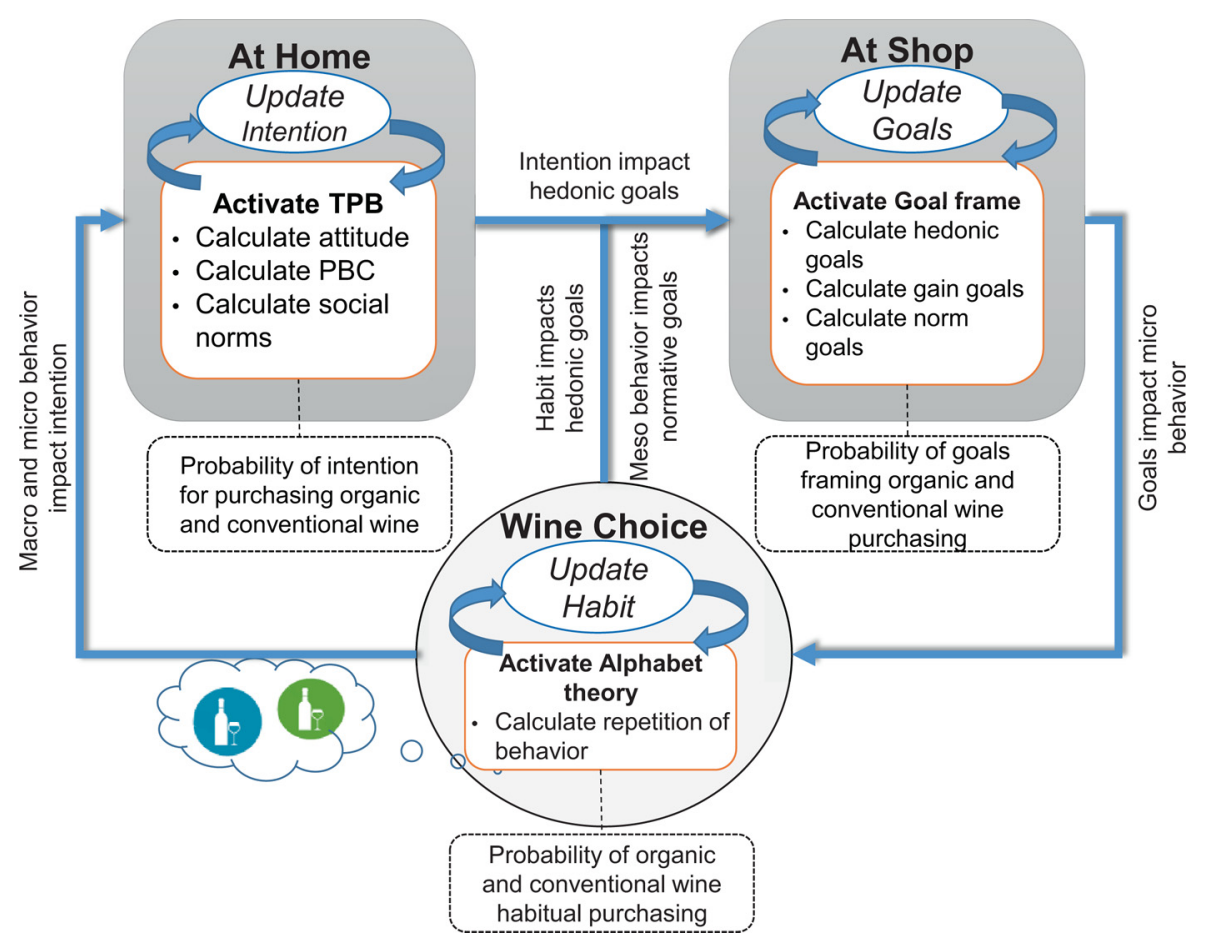

Fig. 1. Household wine-related decision-making process.

between organic and conventional wines, at home based on their attitude, price of wine at last shopping, and advice of neighbors. Every time they go shopping for wine, they consider the available wine retailers and visit the closest one. We assume that the retailers always meet the market demand, and no stock-out condition is allowed. The final choice is made at the shop according to the Goal Framing Theory. The Alphabet Theory is used to describe the effect of habit on purchasing behavior. These probabilistic theory-driven empirical rules of household behavior result in dynamic changes in wine preferences. Different control factors, such as wine prices and organic informational-educational campaigns, drive changes in consumers' behavior (See Appendix C.3 in supplementary data).

\section{Results and discussion}

\subsection{Sensitivity analysis, calibration, and validation of results}

We run an extensive sensitivity analysis. It indicates that the model is most sensitive to the weight of social norms and normative goals. The latter two parameters relate to a social phenomenon known as "undercover altruism" in organic purchasing behavior (Scalco, 2017). It assumes that individuals may choose to hide their virtuous, moral behavior in public to avoid awkward social situations, and integrate within a social group. Hence, in the absence of social pressure, people may be more likely to choose organic wines, bringing our attention to social norms and normative goals throughout the paper (See Appendix D.1 in supplementary data).

The values of parameters in the baseline setting are derived either from experimental data or by calibration using the One-Factor-At-aTime (OFAT) method. We calibrate the model by adjusting the two most sensitive parameters to align the model results with available observed purchasing data. We made sure that the ratio of organic wine purchases stays constant at around $7-10 \%$ over 600 weeks (refer to Fig. 2), as consistent with the trend of organic wine market share from 2014 to 2018 (See Appendix D.2 in supplementary data). Steady trends are also noticed for similar behaviors like the annual volume of wine consumption and per capita wine consumption (Statista, 2017). Most probably, the strength of the effect of a social context on the wine purchasing behavior results in the locked-in consumption pattern, reported earlier (refer to Janssen and Jager (1999)).

For validation purposes, we used empirical data reported by Ogbeide (2013). We predict the intention of purchasing organic wine when the price of organic wines is $10 \%, 20 \%$ and $40 \%$ (and more) higher than conventional wines and then compare the estimated results with the available data in the baseline scenario. Appendix D. 3 in supplementary data reports the validation parameters and results.

\subsection{Market-based instruments: restructuring the tax system}

The objective of structural interventions is to increase the attractiveness of the desired behavior through changing the contextual factors shaping the decision-making process. Three types of structural intervention include availability, financial, and legal measures (Steg and Vlek, 2009). For example, in terms of availability, the choice of an ecoharmful option can become less attractive when there are new ecofriendly alternatives. In our case, this strategy would limit the availability of conventional wines in stores and increase organic wine supply. This idea seems practically unrealistic in Australia since wine sales are decentralized.

Using financial measures would make the cost of positive pro-environmental behaviors cheaper than the cost of negative behaviors. Research on the consumption of alcohol confirms that selling alcoholic drinks at lower prices increases alcohol consumption and affects human health. Therefore, we did not consider this option. Instead, we assumed increasing the price of conventional wines through taxes.

In Australia, alcohol taxation has a long history and changed many times. Currently, two systems are in place: one taxes beer and spirits based on volumes ('excise tax'), and another one taxes wine based on value ('wine equalization tax, WET) (Parliament of Australia, 2015). WET is $29 \%$ of the final wholesale price of wine, which eventually is paid by consumers. With $10 \%$ Goods and Services Tax (GST) applied to retailers' margin, the total tax of a wine bottle is about $40 \%$.

We propose four hypothetical scenarios in which WET increases by $17 \%, 21 \%, 52 \%$, and $70 \%$ only on conventional wines. By doing so, WET changes from $29 \%$ to $35 \%, 40 \%, 45 \%$ and $50 \%$ level. We test these scenarios after the market saturation point, at week 150, when all the 


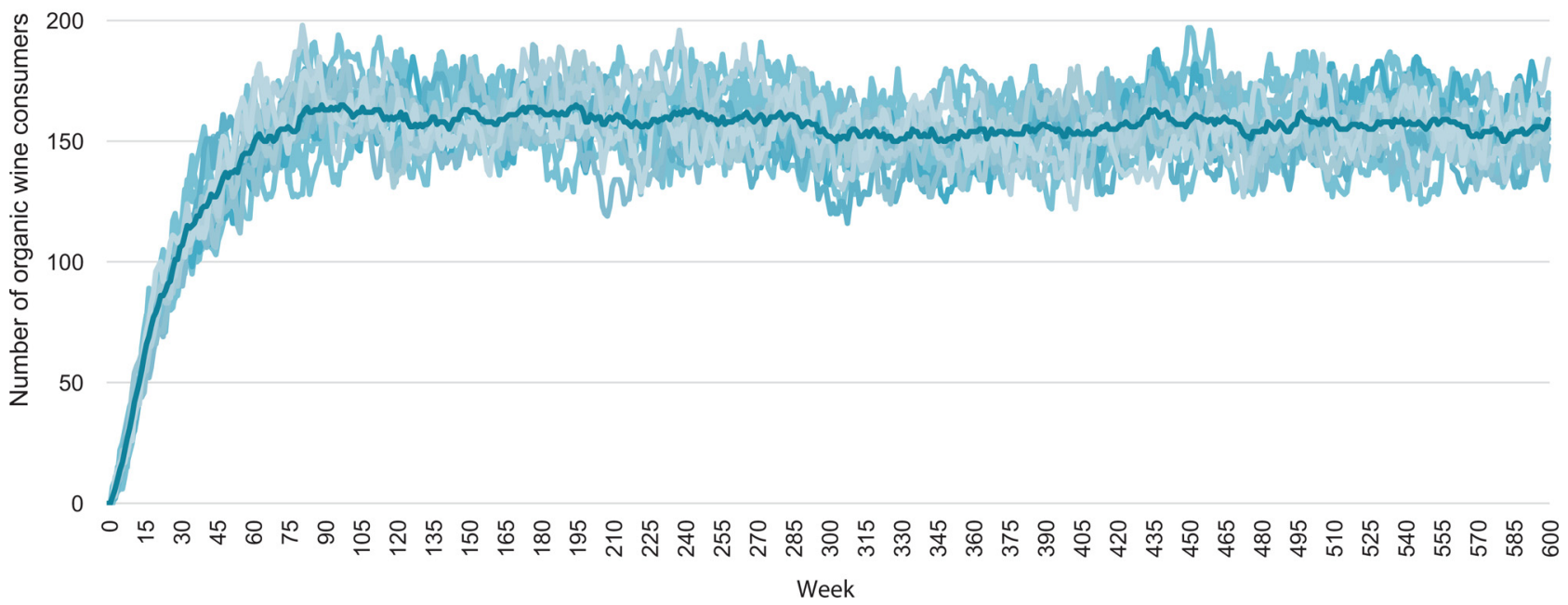

Fig. 2. The result for the baseline scenario (20 runs) showing the variability in the model caused by stochastic parameters describing possible variations in human preferences and behavior.

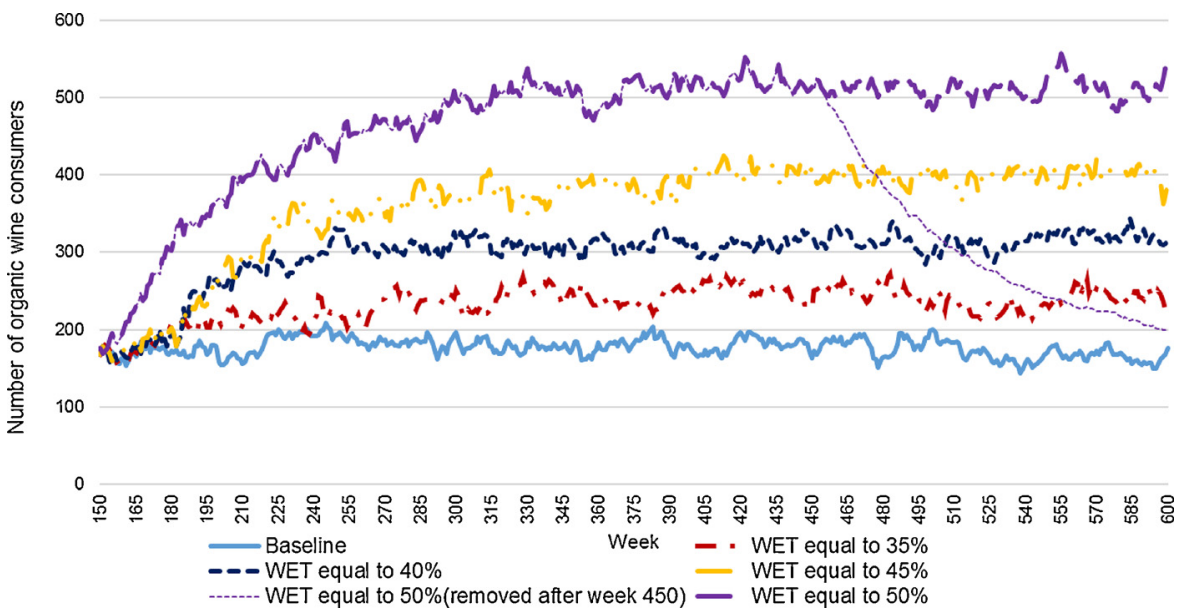

Fig. 3. Comparing the diffusion of organic wine purchasing behavior among households in different scenarios of structural interventions. The dashed line indicates the dynamics of behavior when the 50\% WET is removed after week 450 .

households purchased wine at least once, and their wine preferences are known. Fig. 3 represents how applying different taxation scales on conventional wines can change the ratio of organic wine purchasers.

By imposing additional taxes, the final price of AU\$10 per bottle increases to AU\$10.35, AU\$10.71, AU\$11.06, AU\$11.42, respectively. This increases the ratio of organic wine consumers from $8.5 \%$ to $25 \%$ over 600 weeks. Research on wine price value shows that the demand for cheap wines is highly price-elastic (Hooke, 2016), although there is little agreement about magnitudes. For example, the estimation of price elasticity for wine in France is $0.9-1$, in the United States 0.44-1.654, and in World it is $0.7-1.11$. Wine price elasticity in Australia is reported to vary between 1 and 1.8 (Tsolakis et al., 1983). Estimates of price elasticity of demand for wine confirm the validity of the trend we see in the simulation results.

Notably, if $20 \%$ extra tax on conventional wine is removed at week 450 , the percentage of organic wine consumers drops but stays slightly higher than the baseline (11\% compared to $8.5 \%)$. Once new habits are formed, in response to changes in the price structure, they are likely to stay even after the measure is relaxed.

\subsection{Persuasive intervention: informational marketing}

Persuasive interventions aim to influence the attitude, perception, and norms of individuals and groups without changing the contextualexternal factors. There are three types of persuasive interventions. The first type focuses on increasing individual knowledge to promote certain behavior, say, create positive attitudes toward green alternatives. Information campaigns are considered useful in communicating the pros and cons of alternatives (Steg and Vlek, 2009). The second category aims at strengthening the PBC of consumers to act in a certain way, for example, by motivating altruistic behavior when promoting pro-environmental actions, creating a commitment, and implementing individualized social marketing. Finally, the third category reinforces social norms by informing consumers about the behavior of others, role models, in particular. For environmental behaviors, which are easy, convenient, and inexpensive to adopt (like wine shopping), the first category of informational strategies appears to be an effective motivational approach. Hence, we explore to what extent educating households and increasing their organic wine awareness can change the number of organic consumers.

Over the last 10 years, due to increased awareness about the 
negative impacts of alcohol, global wine markets have experienced a declining trend. The percentage of Australian everyday wine drinkers has significantly dropped from $20 \%$ in 2007 to $13 \%$ in 2017 because of an alcohol education program by the government (Wine Australia, 2018). However, Australia has no comprehensive program to raise public awareness about organic food and drinks, and still price, lack of trust, and lack of knowledge are among the top three barriers for buying organic food (Lawson et al., 2018).

To understand what set of actions can promote organic wine awareness, we benchmark a successful program established in Sweden to educate people about organic products. Swedish people are globally known for their high per capita purchase of organic foods and beverages, and this trend is now apparent in organic wine consumption (Vin-Exchange Group, 2018). In 2013, Swedish state alcohol monopoly, Systembolaget, aimed to increase the assortment of organic drinks to $10 \%$ by 2020 (Szolnoki and Borchert, 2016). Since then, it has started to design and execute a set of programs toward raising public awareness around organic drinks and wine, in particular. Clearly labeling organic wines, providing organic alternatives for popular brands, pushing shops and hotels to offer more organic wines, employing organic wine experts, and training store staff were the main practices employed (Karlsson, 2014). A special TV program, Kalla Fakta, about differences between conventional and organic wines had a big impact (Szolnoki and Borchert, 2016).

Along with customers, Swedish monopoly has issued and passed a sustainable Code of Conduct for importers, and producers. Systembolaget has already achieved $10 \%$ of organic sales volume in 2016, 4 years ahead of the proposed schedule (Systembolaget, 2017). Despite having a small wine market with only five million regular wine drinkers, 51.2\% have stated their preference for organic wine in 2017 (The DIVA Network, 2017).

Inspired by this process, we propose two hypothetical scenarios where the health and environmental benefits of organic wine are advertised moderately or intensely. In terms of model parameters, this means that health concerns of household $i$ at time $t\left(F_{A i 1}(t)\right)$ is increased slightly (by a uniform distribution in the interval $[0,0.1]$ ) or mildly (by a uniform distribution in the interval [0.1, 0.2]). In addition, agents learn about the environmental impacts of organic food and wine at a different pace depending upon their learning ability and the intensity of informational advertising. Household $i$ acquires the knowledge, at the rate of intensity level times learning ability. As the environmental awareness of consumer $i$ at time $t$ grows $\left(F_{A i 2}(t)\right)$, the probability of gaining a positive attitude toward organic wine increases.

Similarly, we initiate these scenarios after week 150, when the number of organic wine consumers levels off. Fig. 4 presents how moderate and intense informational marketing can change the percentage of organic wine purchasers. Sustainable Brand Insight reported that through Systembolget sustainability programs, including education about sustainability issues and the risk of alcohol consumption, the number of Swedes who became aware and smart about socio-environmental issues has grown by $8 \%$ in just one year (Szolnoki and Borchert, 2016). Our model output shows a $7 \%$ growth in the number of organic wine consumers (from $8.5 \%$ in week 150 to $15.5 \%$ in week 600 ). The consistency between model results and observed data confirms the validity of this model. This considerable growth in the ratio of organic users highlights the significant influence that media and education can have on increasing demands for sustainable products.

We then assume that the marketing program returns to a low-intensity level in week 450. The percentage of organic wine consumers remained 1.5 times higher compared to the baseline scenario ( $8 \%$ vs. $12 \%)$. Note that the drop in organic wine consumers after the informational intervention suspension (3.5\% reduction) is considerably smaller compared to the tax suspension (20\% reduction). In other words, the self-learning ability of households is greater than induced by informational strategies compared to structural strategies. It is not only the experience from wine shopping that helps the agents to learn but also the information about organic production that they continuously receive. This highlights that promoting context-dependent repetition of behavior in combination with sharing information about that behavior may shape lasting habits.

\subsection{Combined intervention}

According to Steg and Vlek (2009), to evaluate the effectiveness of an intervention, its singular influence should be compared to its influence in combination with others. They emphasized that combined interventions are more likely to be successful in changing behavior. Proenvironmental choices face both contextual and informational barriers, while often, interventions focus only on one of them. Additionally, different target groups have different motivational, habitual, and contextual factors, so policy interventions should reach different audiences to make a significant impact.

Hence, we run a combined tax-marketing intervention and compare results with one structural and one information scenario with the highest effectiveness in changing behavior (see Figs. 5). Fig. 6 demonstrates the spatial diffusion of behavior in different scenarios.

Our results indicate a $44 \%$ increase (from $8.5 \%$ to $52.5 \%$ ) in the percentage of households with organic wine preference compared to the baseline. This is $28 \%$ higher than tax, $42 \%$ higher than informational marketing, and $20 \%$ higher than by applying these interventions, separately. The emergent effect from various interventions is non-additive, with the combined scenario exhibiting a nonlinear growth in the share of households preferring organic wine. The number of people with organic wine preferences continues to grow even after the forecasted period, reaching up to 1400 in week 1000 .

These results highlight that:

(1) Behavioral shifts occur when the social pressure for purchasing conventional wine reduces. Jager and Ernst (2017) suggest this phenomenon is caused by co-dependent behaviors, where individual behavior is amplified by its social environment. They state that "the coupling results in social processes that may become selfamplifying: the more people change, the stronger the social pressure on other people to change as well."

(2) A cascade of behavior changes for purchasing organic wine is triggered by getting over the $35 \%$ tipping point, which can be achieved only by combining two strategies. This radical change does not occur even if more than a third of the population adopt organic wine in response to separate interventions.

(3) Conformity rather than social learning plays the dominant role in purchasing contagious products, including wine. As organic wine purchasing behavior gains more visibility, it is more likely to gain social approval. The norm for conventional wine purchasing in a vicious cycle can shift to organic wine purchasing in a virtuous cycle and get reinforced.

Notably, the learning rate of households in the combined scenario $(28.5 \%)$ is significantly higher than in the persuasive scenario $(12 \%)$ and structural scenario (11\%). Similar to the real-world, household agents learn proactively from the environment and accumulate previous shopping experience to do habitual shopping. These habitual behaviors tend to persist unconsciously and automatically. This shows how the model can be useful to identify what duration of intervention is sufficient to promote the context-dependent repetition of the behavior for habit formation.

\section{Conclusions and implications}

This paper focuses on the demand side of organic food market and quantifies the cumulative impacts of behavioral changes among heterogeneous consumers, prone to behavioral biases and social interactions. We operationalized multiple behavioral theories to understand 
600

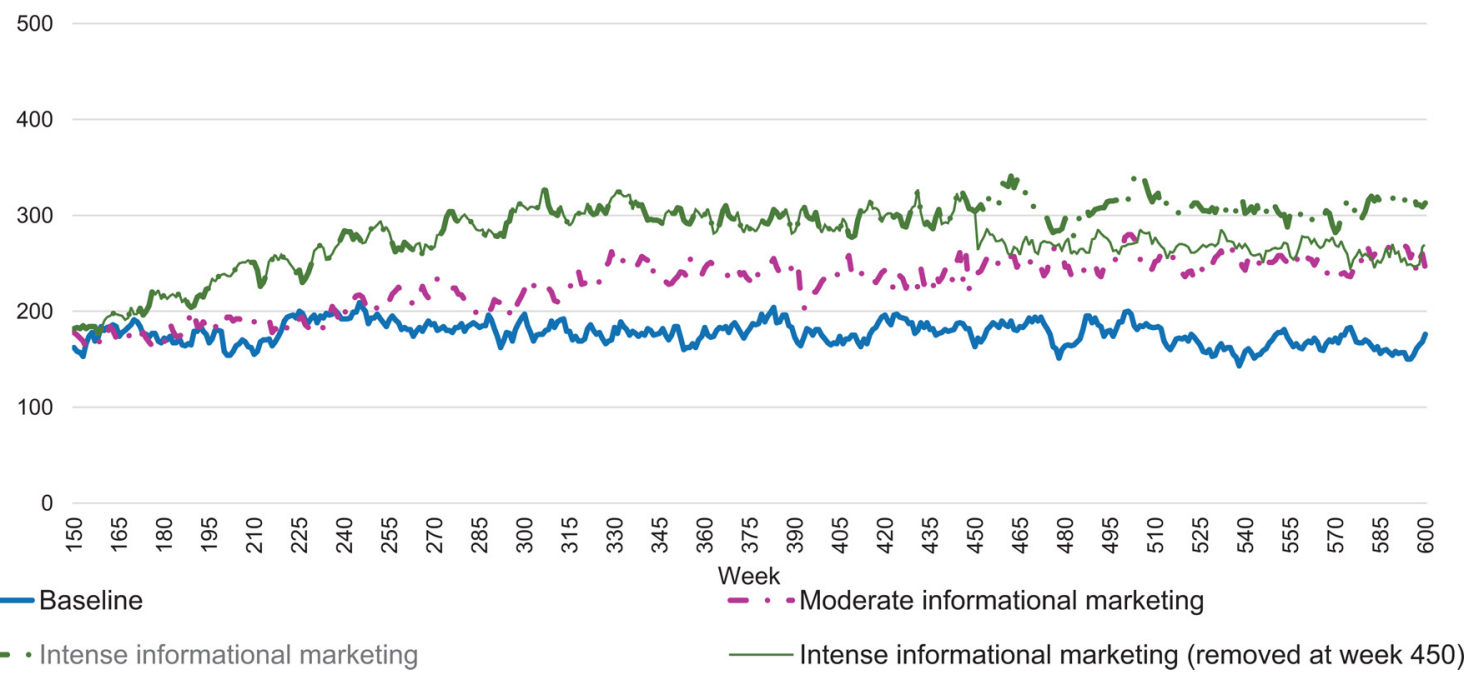

Fig. 4. Comparing the diffusion of organic wine purchasing behavior among households in different scenarios of persuasive intervention. The dashed line presents the dynamics of organic wine consumers after the intense marketing program stopped.

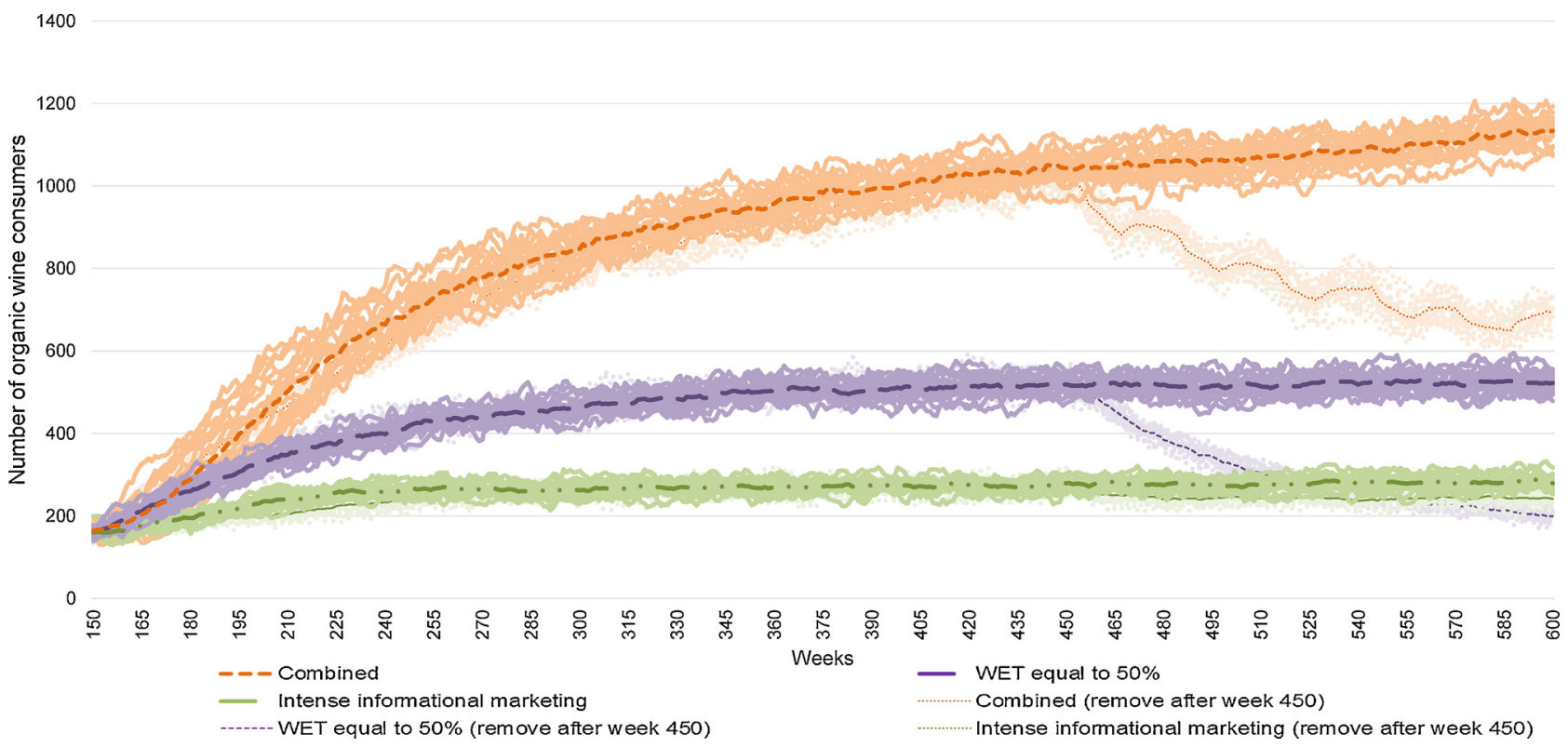

Fig. 5. Comparing the diffusion of organic wine purchasing behavior among households following structural, persuasive and combined interventions (after 20 runs). Dashed lines present the dynamics of organic wine consumers after interventions are suspended.

the key elements of wine purchasing behavior, such as intention, habits, and personal goals. ABMs offer a unique opportunity to combine various social theories in a meaningful way and to understand how various theories interact and affect the overall performance of the system. This allows us to comprehensively explore the dynamics of purchasing decisions in different situations (i.e., shopping environment, house, etc.), understand the influence of context on the action, identify potentials for influencing the preferences, and bridge the gap between intention and behavior. We realized that the application of theories that focus on changing behavior (e.g., goal framing theory) in conjunction with theories that emphasize explaining the decision-making process (e.g., TPB) can improve our understanding of how customer behavior is formed. However, we should also remember that while studying a certain behavior through multiple lenses can provide new insights, it may also introduce undesired complexity and make the model development process time-consuming and model results harder to interpret.
A good balance between detail and functionality should be maintained.

We take organic wines as an example, but the approach is transferrable to analyze other food markets where consumers choose between conventional and organic products. We develop a spatial ABM grounded in theory and data to understand wine purchasing behavior. The model could be a part of the extended supply chain framework (Taghikhah et al., 2019), that highlights the significance of raising consumer awareness and motivating behavioral shifts for reducing the environmental impacts of food production. We believe that the role of consumers and their preferences is an important factor in shaping the transition to a sustainable food supply chain.

Using ORVin, we explore the role of different policy interventions such as taxation and public awareness campaigns in promoting the demand for organic wine. A combined market and information-based policy is more effective in promoting organic wine preference than applying these policies separately. This non-additive effect of policies is 

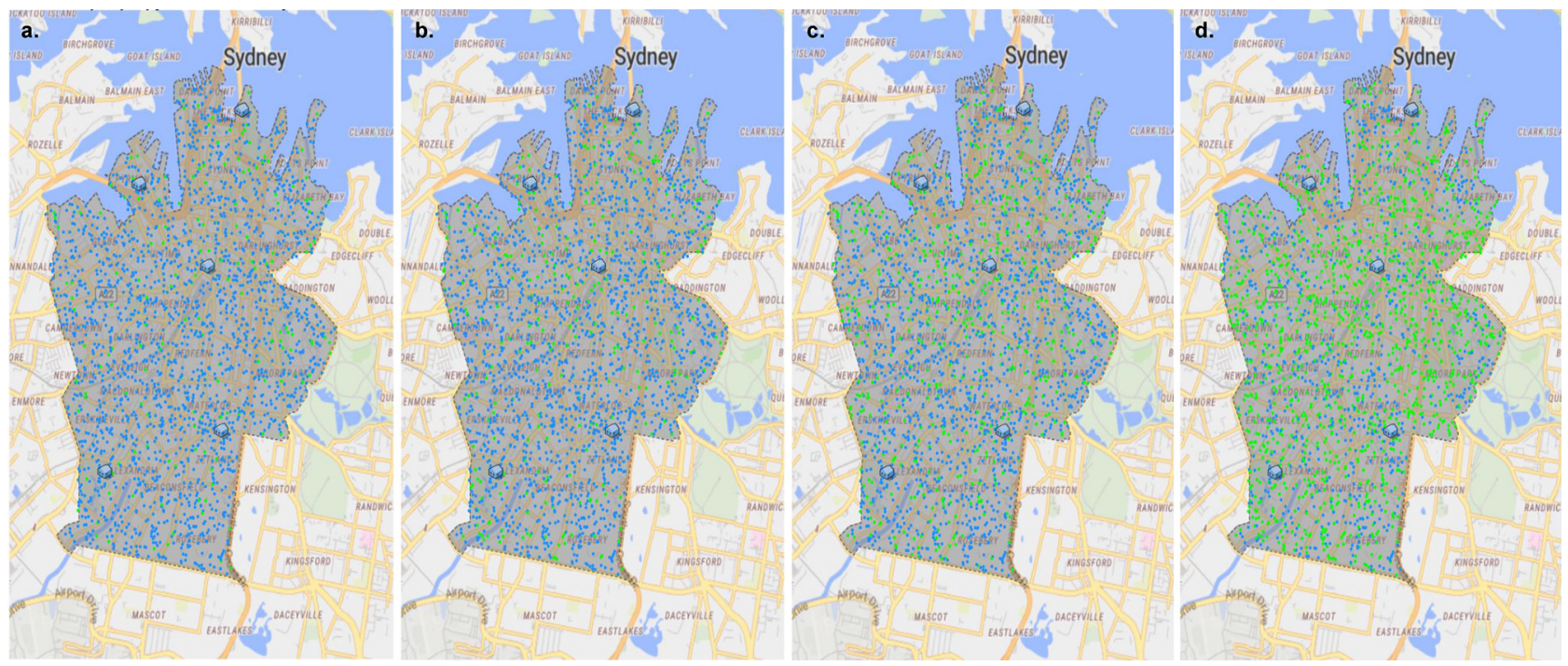

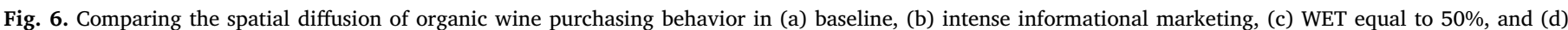

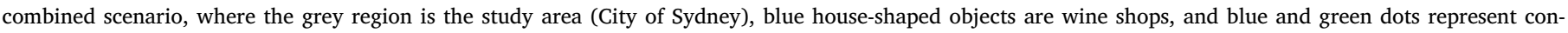
ventional and organic wine consumers, respectively.

an emergent property in this system and may be explained by undercover altruism. This niche market can be tipped to a critical mass of acceptance only in this combined scenario when more than $35 \%$ of the population switch to organic wine. This finding is important for increasing the adoption of organic vice products where the willingness to pay is profoundly lower than for virtue products, even with the same price premiums. Organic vice products suffer from negative quality inferences, which can be reduced in social consumption situations/environments (Mollen et al., 2013). Therefore, if the concerns for public self-image and norm conformance representing undercover altruism are alleviated, the number of organic vice consumers is expected to surge.

Although the examined strategies are hypothetical, they have realworld policy implications for the food and wine sectors. From a food marketing perspective, while big supermarkets and food companies push for launching alternative organic food products, the small market size, and low willingness to pay for them hamper their prosperity. To successfully promote organic vice product lines, a combination of price promotion and normative cues can create major change. Price promotions are effective in attracting new consumers. Cues promoting organic purchasing as a common norm manipulate people's anticipation about possible reactions of others (conventional consumers) and allow them to make a moral choice.

From an agricultural perspective, the Australian Grape and Wine Authority is actively looking for new methods and technologies to enhance the sustainability of wine industry and improve resource management (Australia, 2019). They emphasize that organic is most likely to become a major competitive advantage in the international market. ORVin contributes to this debate, adding insights about how Australian consumers' interests in eco-friendly wines can help to expand the organic trend domestically. It also tells policymakers how to provide additional support for organic farmers by changing consumers' expectations about the wine choice of others. From the health perspective, ORVin can help designing programs for encouraging healthier lifestyles and reducing the health-environmental risks of wine drinking.

There are several limitations in our study calling for future research. So far, the model is largely based on theory and published data. As for other ABMs, we make simplifying assumptions about the real world system, which could be advanced. We assume that the same products, two types of wines, organic and conventional, are available across all retailers and that all their characteristics (taste, color, packaging, etc.) are the same, except for their price. Another limitation in ORVin is that the simulated decision of households is limited to purchasing either organic or conventional wines, while probably both wine types may be purchased at the same time. Finally, a broader range of data should be collected to initialize all the parameters with empirical data and avoid unnecessary biases so that a better calibration and validation can be performed. In addition to checking sensitivity with the OFAT method, global sensitivity analysis can be conducted to reveal how model variables interact and influence each other. At the same time, since most of the decision factors incorporated in the models are common for various food types, we think that by applying a few changes in the model, it could also be used to explore the uptake of other organic products, not just wines.

\section{Declaration of Competing Interest}

The authors declare that they have no known competing financial interests or personal relationships that could have appeared to influence the work reported in this paper.

\section{Acknowledgements}

The first author would like to thank Faculty of Engineering and IT (FEIT), University of Technology Sydney, for the research scholarship.

Authors wish to thank the editor and one anonymous reviewer for their valuable comments on this manuscript.

We also thank MS. Sandy Hathaway, industry analyst from Wine Australia, for assisting with organic wine market data, Dr Ante Prodan, from Western Sydney University, for his technical help in model development, and Prof Mikhail Anufriev, from University of Technology Sydney for his constructive comments on the food policies.

\section{Appendix A. Supplementary data}

Supplementary material related to this article can be found, in the online version, at doi:https://doi.org/10.1016/j.envsci.2020.04.001.

\section{References}

Ajzen, I., 1985. From intentions to actions: A theory of planned behavior. In Action control. Springer (pp. 11-39).

Amato, M., Ballco, P., López-Galán, B., De Magistris, T., Verneau, F., 2017. Exploring consumers' perception and willingness to pay for "Non-Added Sulphite" wines through experimental auctions: a case study in Italy and Spain. Wine Econ. Policy 6 (2), 146-154. https://doi.org/10.1016/j.wep.2017.10.002. 
Australia, W., 2019. About Wine Australia. Retrieved from. https://www.wineaustralia. com/about-us.

Barber, N., 2012. Consumers' intention to purchase environmentally friendly wines: a segmentation approach. Int J Hospit Tourism Admin 13 (1), 26-47.

Bernabéu, R., Prieto, A., Díaz, M., 2013. Preference patterns for wine consumption in Spain depending on the degree of consumer ethnocentrism. Food Qual Prefer. 28 (1), $77-84$.

Boncinelli, F., Dominici, A., Gerini, F., Marone, E., 2019. Consumers wine preferences according to purchase occasion: personal consumption and gift-giving. Food Qual. Prefer. 71, 270-278. https://doi.org/10.1016/j.foodqual.2018.07.013.

Castex, V., Tejeda, E.M., Beniston, M., 2015. Water availability, use and governance in the wine producing region of Mendoza, Argentina. Environ. Sci. Policy 48, 1-8. https:// doi.org/10.1016/j.envsci.2014.12.008.

D'amico, M., Di Vita, G., Chinnici, G., Pappalardo, G., Pecorino, B., 2014. Short food supply chain and locally produced wines: factors affecting consumer behavior. Ital. J. Food Sci. 26 (3) Retrieved from. http://ezproxy.lib.uts.edu.au/login?url=https:// search-proquest-com.ezproxy.lib.uts.edu.au/docview/1564228621?accountid = 17095.

Di Vita, G., Chinnici, G., D'Amico, M., 2014. Clustering attitudes and behaviours of Italian wine consumers. Calitatea 15 (S1), 54. Retrieved from. http://search.proquest.com/ docview/1509435970/.

Duncan, D.T., Kawachi, I., Subramanian, S., Aldstadt, J., Melly, S.J., Williams, D.R., 2013. Examination of how neighborhood definition influences measurements of youths' access to tobacco retailers: a methodological note on spatial misclassification. Am. J. Epidemiol. 179 (3), 373-381. https://doi.org/10.1093/aje/kwt251.

Erdlenbruch, K., Bonté, B., 2018. Simulating the dynamics of individual adaptation to floods. Environ Sci Policy 84, 134-148. https://doi.org/10.1016/j.envsci.2018.03. 005.

Fleming, A., Rickards, L., Dowd, A.-M., 2015. Understanding convergence and divergence in the framing of climate change responses: an analysis of two wine companies. Environ. Sci. Policy 51, 202-214. https://doi.org/10.1016/j.envsci.2015.04.003.

Forbes, S.L., 2014. Wine Purchasing: Planned or Unplanned Behaviour.

Garcia, R., Rummel, P., Hauser, J., 2007. Validating agent-based marketing models through conjoint analysis. J. Bus. Res. 60 (8), 848-857. https://doi.org/10.1016/j. jbusres.2007.02.007.

Galati, A., Schifani, G., Crescimanno, M., Migliore, G., 2019. "Natural wine" consumers and interest in label information: an analysis of willingness to pay in a new Italian wine market segment. J. Clean. Prod. 227, 405-413. https://doi.org/10.1016/j. jclepro.2019.04.219.

Guido, G., Prete, M.I., Peluso, A.M., Maloumby-Baka, R.C., Buffa, C., 2010. The role of ethics and product personality in the intention to purchase organic food products: A structural equation modeling approach. Int. Rev. Econ. 57 (1), 79-102. https://doi. org/10.1007/s12232-009-0086-5.

Hidalgo-Baz, M., Martos-Partal, M., González-Benito, Ó., 2017. Assessments of the quality of organic versus conventional products, by category and cognitive style. Food Qual. Prefer. 62, 31-37. https://doi.org/10.1016/j.foodqual.2017.06.008.

Hooke, H., 2016. GST and wine. The Real Review.

Hu, H.-h., Lin, J., Qian, Y., Sun, J., 2018. Strategies for new product diffusion: Whom and how to target? J. Bus. Res. 83, 111-119. https://doi.org/10.1016/j.jbusres.2017.10. 010.

Hyland, C., Bradman, A., Gerona, R., Patton, S., Zakharevich, I., Gunier, R.B., Klein, K., 2019. Organic diet intervention significantly reduces urinary pesticide levels in US children and adults. Environ. Res 171, 568-575. https://doi.org/10.1016/j.envres. 2019.01.024.

Intergovernmental Panel on Climate Change, 2019. Climate Change and Land. Retrieved from https://www.ipcc.ch/site/assets/uploads/2019/08/2f. [HYPHEN]Chapter [HYPHEN]5 FINAL.pdf.

Jager, W., Ernst, A., 2017. Introduction of the Special Issue "Social Simulation in Environmental Psychology". Elsevier.

Janssen, M., Jager, W., 1999. An integrated approach to simulating behavioural processes: a case study of the lock-in of consumption patterns. J. Artif. Soc. Soc. Simul. 2 (2), 21-35. Retrieved from. http://jasss.soc.surrey.ac.uk/2/2/2/2.pdf.

Karlsson, B., 2014. Sales of Organic Wines (in Sweden). BKWineMagazine.

Kangur, A., Jager, W., Verbrugge, R., Bockarjova, M., 2017. An agent-based model for diffusion of electric vehicles. J. Environ. Psychol. 52, 166-182. https://doi.org/10. 1016/j.jenvp.2017.01.002.

Kushwah, S., Dhir, A., Sagar, M., 2019. Understanding consumer resistance to the consumption of organic food. A study of ethical consumption, purchasing, and choice behaviour. Food Quality and Preference 77, 1-14. https://doi.org/10.1016/j. foodqual.2019.04.003.

Lawson, A., Cosby, A., Baker, D., Shawn, L., lefley, E., Soha, A., et al., 2018. Australian Organic Market Report 2018. Retrieved from. . https://austorganic.com/wpcontent/uploads/2018/04/AustOrganicMarketReport2018_spreads_digital.pdf.

Lee, H.-C., Chang, C.-T., Cheng, Z.-H., Chen, Y.-T., 2018. Will an organic label always increase food consumption? It depends on food type and consumer differences in health locus of control. Food Qual Prefer 63, 88-96. https://doi.org/10.1016/j. foodqual.2017.08.002.

Lindenbrg, S., Steg, L., 2013. Goal-framing theory and norm-guided environmental behavior. Encouraging sustainable behaviour $37-54$

Li, Y., Zhang, D., Thapa, J.R., Madondo, K., Yi, S., Fisher, E., Pagán, J.A., 2018. Assessing the role of access and price on the consumption of fruits and vegetables across New York City using agent-based modeling. Prev. Med. 106, 73-78.

Lockshin, L., Corsi, A.M., 2012. Consumer behaviour for wine 2.0: A review since and future directions. Wine Economics and Policy 1 (1), 2-23.

Loose, S.M., Lockshin, L., 2013. Testing the robustness of best worst scaling for crossnational segmentation with different numbers of choice sets. Food Qual. Prefer. 27 (2), 230-242. https://doi.org/10.1016/j.foodqual.2012.02.002.

Martinez-Carrasco, L., Brugarolas, M., Martinez-Poveda, A., 2005. Quality wines and wines protected by a designation of origin: identifying their consumption determinants. J. Wine Res. 16 (3), 213-232. https://doi.org/10.1080/09571260600556690.

Mascitelli, B., Lobo, A., Phan, D., Bez, N., Low, D., 2014. Australian organic market report 2014. Biological Farmers of Australia, Chermside.

Mollen, S., Rimal, R.N., Ruiter, R.A., Kok, G., 2013. Healthy and unhealthy social norms and food selection. Findings from a field-experiment. Appetite 65, 83-89. https://doi. org/10.1016/j. appet.2013.01.020.

Mosier, S.L., Thilmany, D., 2016. Diffusion of food policy in the US: The case of organic certification. Food policy 61, 80-91. https://doi.org/10.1016/j.foodpol.2016.02. 007.

Niamir, L., Filatova, T., Voinov, A., Bressers, H., 2018. Transition to low-carbon economy: Assessing cumulative impacts of individual behavioral changes. Energy policy 118, 325-345. https://doi.org/10.1016/j.enpol.2018.03.045.

O'Mahony, B., Lobo, A., 2017. The organic industry in Australia: current and future trends. Land Use Policy 66, 331-339. https://doi.org/10.1016/j.landusepol.2017.04. 050 .

Ogbeide, O.A., 2013. Consumer Willingness to Pay Premiums for the Benefits of Organic Wine and the Expert Service of Wine Retailers. Doctor of Philosophy), The University of Adelaide.

Panzone, L.A., 2014. Why are discounted prices presented with full prices? The role of external price information on consumers' likelihood to purchase. Food Qual. Prefer. 31, 69-80. https://doi.org/10.1016/j.foodqual.2013.08.003.

Parliament of Australia, P. B. O, 2015. Alcohol Taxation in Australia. Retrieved from. . https://www.aph.gov.au/About_Parliament/Parliamentary_Departments/ Parliamentary_Budget_Office/Publications/Research_reports/Alcohol_taxation_in_ Australia.

Pizzigallo, A., Granai, C., Borsa, S., 2008. The joint use of LCA and emergy evaluation for the analysis of two Italian wine farms. J Environ Manage 86 (2), 396-406. https:// doi.org/10.1016/j.jenvman.2006.04.020.

Pomarici, E., Vecchio, R., 2014. Millennial generation attitudes to sustainable wine: an exploratory study on Italian consumers. J. Clean. Prod. 66, 537-545. https://doi.org/ 10.1016/j.jclepro.2013.10.058.

Rangoni, R., Jager, W., 2017. Social dynamics of littering and adaptive cleaning strategies explored using agent-based modelling. J. Artif. Soc. Soc. Simul. 20 (2). https://doi. org/10.18564/jasss.3269.

Sampson, R.J., 1993. The community context of violent crime. Sociol. Public Agenda 259-286. https://doi.org/10.4135/9781483325484.n13.

Scalco, A., 2017. Organic Food Purchase Behavior: the Complex Relationship Between Consumer's Attitude and Social Norms. University of Verona.

Schäufele, I., Hamm, U., 2017. Consumers' perceptions, preferences and willingness-topay for wine with sustainability characteristics: a review. J. Clean. Prod. 147, 379-394. https://doi.org/10.1016/j.jclepro.2017.01.118.

Schäufele, I., Hamm, U., 2018. Organic wine purchase behaviour in Germany: Exploring the attitude-behaviour-gap with data from a household panel. Food Qual. Prefer. 63, 1-11. https://doi.org/10.1016/j.foodqual.2017.07.010.

Shih, R.A., Parast, L., Pedersen, E.R., Troxel, W.M., Tucker, J.S., Miles, J.N., et al., 2017. Individual, peer, and family factor modification of neighborhood-level effects on adolescent alcohol, cigarette, e-cigarette, and marijuana use. Drug Alcohol Depend. 180, 76-85. https://doi.org/10.1016/j.drugalcdep.2017.07.014.

Statista, 2017. Wine Industry Australia - Statistics and Facts. Retrieved from. https:// www.statista.com/topics/4000/wine-industry-in-australia/.

Steg, L., Vlek, C., 2009. Encouraging pro-environmental behaviour: an integrative review and research agenda. J. Environ. Psychol. 29 (3), 309-317. https://doi.org/10.1016/ j.jenvp.2008.10.004.

Systembolaget, 2017. Systembolaget's Responsibility Report. pp. 128.

Szolnoki, G., Borchert, J., 2016. The organic wine boom on the swedish wine market. Meininger's Wine Bus. Int. 5 Retrieved from. https://www.meininger.de/en/winebusiness-international/look-sustainable-sweden.

Tait, P., Saunders, C., Dalziel, P., Rutherford, P., Driver, T., Guenther, M., 2019. Estimating wine consumer preferences for sustainability attributes: A discrete choice experiment of Californian Sauvignon blanc purchasers. J. Clean. Prod. https://doi. org/10.1016/j.jclepro.2019.06.076.

Taghikhah, F., Voinov, A., Shukla, N., 2019. Extending the supply chain to address sustainability. J. Clean. Prod. https://doi.org/10.1016/j.jclepro.2019.05.051.

The DIVA Network, 2017. Overview of the Organic Market. Retrieved from. https:// divawine.com/overview-organic-market/.

Tsolakis, D., Riethmuller, P.C., Watts, G., 1983. The demand for wine and beer. Rev. Marketing Agric. Econ. 51 (430-2016-31363), 131.

Van Doorn, J., Verhoef, P.C., 2011. Willingness to pay for organic products: Differences between virtue and vice foods. Int. J. Mark. Res. 28 (3), 167-180. https://doi.org/10. 1016/j.ijresmar.2011.02.005.

Vin-Exchange Group, 2018. Sweden; a Snapshot of the Wine Sector. Retrieved from. https://en.vinex.market/articles/2016/10/04/sweden_a_snapshot_of_the_wine sector.

Wheeler, S.A., 2008. What influences agricultural professionals' views towards organic agriculture? Ecol Econ 65 (1), 145-154. https://doi.org/10.1016/j.ecolecon.2007. 05.014 .

Wine Australia, 2018. Less Is More: What's Driving Consumer Choices in 2018. Market Bulletin. Retrieved from. https://www.wineaustralia.com/news/market-bulletin/ issue- 100.

Wilbois, K.-P., Schmidt, J.E., 2019. Reframing the Debate Surrounding the Yield Gap between Organic and Conventional Farming. Agron. 9 (2), 82. https://doi.org/10. 3390/agronomy9020082.

Woods, J., Williams, A., Hughes, J.K., Black, M., Murphy, R., 2010. Energy and the food system. Philosophical Transactions of the Royal Society B: Biological Sciences.

Zepeda, L., Deal, D., 2009. Organic and local food consumer behaviour: Alphabet theory. Int. J. Consum 33 (6), 697-705. https://doi.org/10.1111/j.1470-6431.2009.0. 